\section{Vanishing Duodenal Varix: Unreported Presentation Causing Massive Bleeding}

A 63-year-old cirrhotic patient presented with hematemesis. During emergency endoscopy, a bulging varicose cord $3 \mathrm{~cm}$ in length and $1 \mathrm{~cm}$ in diameter suddenly emerged from a small diverticulum located in the second duodenal portion, and on several occasions completely disappeared and reappeared (Figure 1). These changes in size were not related to retching, breathing, or air insufflation. Peristaltic movements seemed to cause the varix changes. After the administration of hyoscine butylbromide $20 \mathrm{mg}$ i.v., the varix remained bloated. A platelet aggregate was seen at its proximal edge, and an injection of $7 \mathrm{ml}$ of ethanolamine oleate was carried out. Two hours later, massive bleeding occurred, and the patient, in an unstable hemodynamic condition, underwent a duodenotomy and suture of the varix. Four days later, the patient died due to multisystem failure.

Changes in the size of duodenal varices related to respiratory movements have been reported (1), but we have not found any other reference to the spontaneous disappearance of duodenal varices during endoscopy. Duodenal varices are located deeper than esophageal varices, and are mostly serosal (2). It is probable that the variceal size changes in our patient were due to some compressive effect in the muscular duodenal layer on the varix during its retroperitoneal to submucosal course. The fact that the varix remained bloated after the administration of a smooth muscle relaxant would reinforce this supposition. Portosystemic shunt is the most effective treatment in preventing rebleeding (3), but the patient's poor clinical condition prevented this procedure. Although sclerotherapy has been considered useful in high-risk patients (4), the rarity of this condition, and the disparity in the types and amounts of substances used in published studies, makes it difficult to draw any meaningful conclusion as to the most effective injection therapy.

R. Campo ${ }^{1}$, E. Brullet ${ }^{1}$, A. Corcuera ${ }^{2}$, D. Joseph ${ }^{3}$

' Digestive Endoscopy Unit

${ }^{2}$ Dept. of Surgery

${ }^{3}$ Dept. of Intensive Care, C. H. Parc Tauli, Sabadell, Spain

\section{References}

1. Jiménez $M$, Pallarés $H$, Romero $R$, Piñar A, Gómez $M$, Herrerias JM. Hemorragia digestiva por varices duodenales. Rev Esp Enf Digest 1994; 85: 209-11.

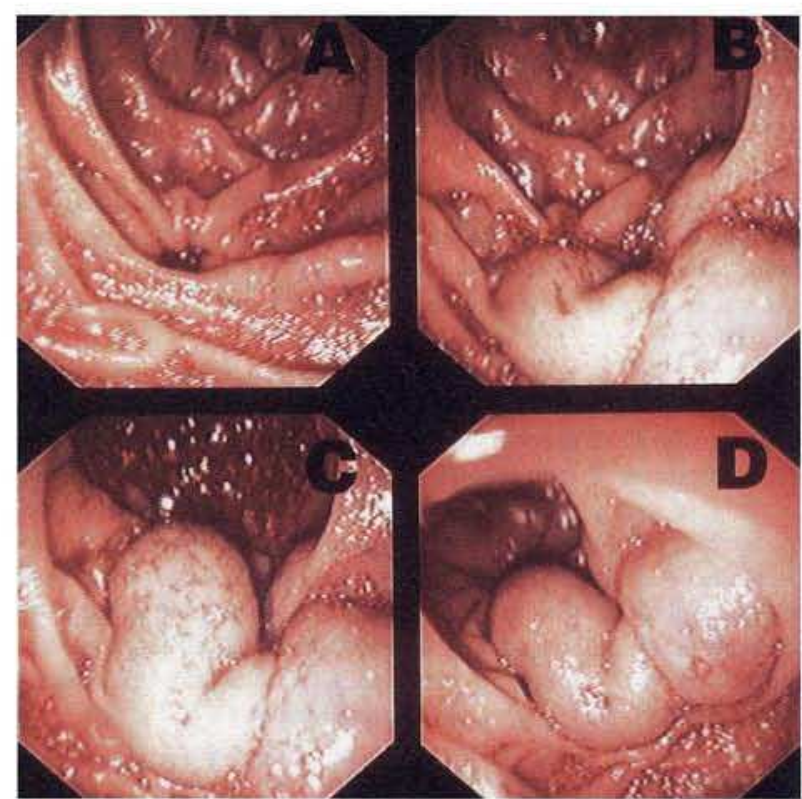

Figure 1a: A small diverticulum is seen in the second duodenal segment b, c A bulging varicose cord $1 \mathrm{~cm}$ in diameter suddenly forms, with the filling direction being proximal to distal. This phenomenon occurred several times. $\mathbf{d}$ The varix remains bloated, and a small platelet aggregate can be clearly seen over the tip of its proximal edge.

2. Hashizume M, Tanoue K, Ohta M, et al. Vascular anatomy of duodenal varices: angiographic and histopathological assessments. Am J Gastroenterol 1993; 88: 1942-5.

3. Khouqeer F, Morrow C, Jordan P. Duodenal varices as a cause of massive upper gastrointestinal bleeding. Surgery 1987; 102: $548-52$.

4. Barbish AW, Ehrinpreis MN. Successful endoscopic injection sclerotherapy of a bleeding duodenal varix. Am J Gastroenterol 1993; 88: 90-2.

Corresponding Author

R. Campo, M.D.

Digestive Endoscopy Unit

C.H. Parc Tauli, Parc Taulí s/n

08208 Sabadell, Spain

Fax: +34-3+7 160646 